\title{
Atropellos a la autonomía de los docentes: Desde la abolición de la tarima hasta la extorsión de profesores ${ }^{1}$
}

\section{Assaults against Professors' Autonomy: From Obliterating the Dais to Extortion and other abuses thereof.}

Juan Guillermo Durán Mantilla

Fecha de recepción: 6 de junio de 2014

Fecha de aprobación: 4 de octubre de 2014

\section{RESUMEN}

Para evidenciar atropellos al derecho a la autonomía del profesor, se llevó a cabo una investigación de carácter cualitativo. En las presentes líneas, describo y analizo críticamente algunos casos concretos de atropello relacionados la tecnificación docente, la homogenización, las actividades institucionales, las evaluaciones del desempeño docente, las asunción de la minoridad del docente, la dependencia institucional, los contratos docentes y los salarios que se les ofrecen. En este artículo, no pretendo dar un ultimátum ni ocultar responsabilidades sino, por el contrario, abrir la discusión.

Palabras clave: atropellos, autonomía, profesor, responsabilidad.

1 Este artículo de investigación y reflexión se enmarca dentro de las actividades del grupo de investigación Persona, instituciones y exigencias de justicia del Centro de Investigaciones socio-jurídicas de la Universidad Católica de Colombia. El artículo es producto del proyecto de investigación Eficacia del sistema interamericano de derechos humanos, el cual fue financiado por la Universidad anteriormente mencionada.

2 Doctor en Derecho de la Universidad de Navarra. Docente e investigador de la Universidad Católica de Colombia y de la Universidad Santo Tomás. Correo electrónico: natanaelernesto@hotmail.com 


\begin{abstract}
In order to evince abuses against the right to professors' autonomy, I conducted a qualitative research. In these lines, I describe and analyze critically specific cases of abuse, which were related to teaching techniques, homogenization, institutional activities, biased assessments, nonage attitudes, institutional dependency, professors' contracts and their salaries. In this article, I do not intend to give an ultimatum or to minimize responsibilities but, on the contrary, to open a discussion.
\end{abstract}

Keywords: Abuses, autonomy, professor, responsibility.

\title{
INTRODUCCIÓN
}

Uno de los derechos del maestro más resonados es su autonomía. En la teoría, no hay duda sobre este derecho, aunque tiene algunos límites, como todo derecho. Los derechos humanos están limitados por los correspondientes deberes y por la coexistencia de los mismos derechos y, por ende, no pueden considerarse absolutos. Sin embargo, en mi experiencia de profesor universitario, he sentido que esa autonomía ha disminuido gradualmente desde hace un tiempo. Esta percepción me motivó a escribir la presente reflexión. En este texto, no me centraré en la esencia del derecho autonómico del profesor; sólo me referiré a algunos hechos que lo atropellan.

En primera instancia, considero que la autonomía conlleva al humano a ser él mismo. Entonces, la autonomía docente es la relación entre el profesor con su ser primero, hombre-docente, que le permite al profesor desarrollarse. La merma de la autonomía del maestro se refleja en muchos aspectos. Comencemos por la eliminación de la tarima en el aula de clases. La tarima era una escala de aproximadamente cuarenta centímetros de altura, hecha de cemento o de madera y ubicada en la parte frontal del salón de clases. En este sitio especial se hallaba el escritorio del profesor y el tablero. Probablemente, ni el lector ni alumnos recuerdan la tal tarima. La vieja tarima era adorada para el maestro y temida por los estudiantes. Cuando los alumnos 
pasaban al frente y se subían en ella, aprendían a expresarse delante de los demás, a hablar en público. Desde la tarima, el profesor veía todo el salón y podía manejar su auditorio. Los alumnos veían al docente en la tarima y no había lugar a distracciones. La tarima también permitía que las ondas de sonido viajaran mejor y, por tanto, el maestro no debía elevar la voz para ser escuchado. Igualmente, la tarima le daba una ventaja visual al docente; no debía exagerar sus movimientos para ser visto y atendido por los dicentes. Mas la tarima ya es sólo un recuerdo. Hoy por hoy, a ras de piso, los profesores tenemos que elevar nuestras voces para ser escuchados y casi que nos vemos obligados a movernos como showmen, o vulgarmente payasos, para llamar la atención de nuestros estudiantes. Mi voz, por ejemplo, se ha cascado de tanto esfuerzo, lo cual ha dado lugar a unos cuantos ingresos económicos a mi fonoaudióloga.

Los maestros hemos pasado de ser objetos de admiración en la tarima a ser objetos de extorsión en el suelo. Según el Defensor del Pueblo, Jorge Armando Otálora, 1.170 profesores han denunciado ser víctimas de extorsión en el país (El Tiempo, 17 de marzo de 2014, p. 4). Incluso, en ciertas ocasiones, las extorsiones han terminado transgrediendo la vida de los profesores. Algunos de esos asesinatos se han asociado con razones ideológicas, lo cual es verídico en Colombia. No obstante, es una lástima que eso suceda porque "ninguna idea merecía un muerto", como decía Bernardo Jaramillo (El Tiempo, 17 de marzo de 2014).

A pesar de que el asesinato y la extorsión a los maestros son hechos sumamente lamentables, este texto no se centrará en ellos. Tampoco se dedicará a analizar la abolición de la tarima. Esos son ejemplos de casos extremos de atropello a los profesores, los cuales, incluí en el título de este artículo para llamar la atención del lector. En este escrito, prefiero concentrarme en examinar casos intermedios de atropello a la autonomía del maestro. 


\section{MéTodo}

La presente investigación se enmarca en un proceso sistemático, crítico y empírico que pretendió aplicarse al problema de investigación, objeto de las presentes líneas. Para el efecto, se recolectaron datos sin medición numérica para descubrir o afinar la pregunta de investigación propuesta.

Dentro de los cánones investigativos más estrictos y tradicionales, mi método y mis fuentes de información no serían apropiados. Sin embargo, considero que la prensa escrita tiene hoy, y desde hace ya mucho tiempo, un inmenso valor investigativo y educativo. Por tanto, debería tomarse como fuente de investigación y reflexión. La alta academia universitaria cometería un grave acto de ignorancia y de arrogancia si descartara el poder de la prensa.

Por lo anterior, para abordar el problema que me atañía, llevé a cabo una investigación cualitativa. Realicé un análisis de contenido de artículos publicados en la prensa escrita colombiana, particularmente en el periódico El Tiempo, desde finales del ańo 2013 hasta finales del primer semestre del 2014 relacionados con el tema de autonomía docente en Colombia. Más precisamente, me centré en dos expertos en educación, Andrés Hurtado García y de Francisco Cajiao, que publican semanalmente en dicho periódico. Ciertamente, podría haber escogido a otros referentes, pero, desde mi ejercicio de la libertad, he escogido a estos dos columnistas renombrados en sus respectivas columnas periódicas.

Además, he utilizado el fruto de mi experiencia docente, mis reflexiones, para fortalecer mi análisis. Considero que mi larga experiencia docente puede elucidar el análisis de contenido para lograr captar el quid del asunto. Entonces, este artículo no es sólo de investigación, sino también de reflexión. Esta reflexión se propicia dentro del marco del derecho de libertad y autonomía del profesor. Asimismo, debo recalcar que seleccioné esta aproximación metodológica porque deseo que este artículo sea más atrayente para los alumnos, quienes actualmente están más habituados a lecturas rápidas y fácilmente inteligibles. 


\section{ANÁLISIS}

\section{¿Causa de los atropellos?}

Antes de iniciar mi análisis sobre los atropellos a los derechos de los maestros, quiero examinar una posible causa de la disminución de la autonomía docente. En épocas pasadas, algunos profesores incurrían ocasionalmente en abusos a los alumnos. Entre esos abusos estaba el terrorismo académico: Los profesores usaban las calificaciones para aterrorizar y controlar a los estudiantes. Así, algunos docentes se atrevían a decir que tal vez sólo uno de sus alumnos se podría graduar con ellos. Para mayor claridad, permítanme citar un ejemplo que conocí de cerca. Un colega, docente universitario, ejercía el "terrorismo sano" con sus alumnos. Él asignaba las calificaciones según el orden alfabético de los apellidos. En un examen, por ejemplo, colocaba 3,5 a todos los estudiantes que estuviesen entre Alzate e Hincapié; si estaban entre Hincapié y Tarazona, 2; 2,5 si se hallaban entre Tarazona y Zamora. Cuando los alumnos le pedían que les mostrara los exámenes para una eventual revisión, les respondía irónicamente que los había quemado en su chimenea porque no servían para nada más. El terrorismo académico como cualquier otro tipo de todo terrorismo (político, religioso, ideológico, etc.) es reprochable. Por eso, finalmente, sucedió lo que tenía que suceder: despidieron a ese profesor de la universidad. A pesar de ser mi colega y amigo, considero que esa medida estuvo bien.

Es probable que los abusos por parte de los docentes sean el origen de los controles actuales. Esos controles al profesor son adecuados dentro de ciertos límites y con razonabilidad. Sin embargo, los controles se han excedido hasta el punto de reducir la autonomía docente. En este caso, el péndulo de la historia se ha ido al otro extremo; como si la tesis de la lucha de los contrarios como motor de la historia postulada por Hegel fuese inexorable. Mas yo preferiría, en esta y en todas las materias, que hallásemos la equidad y el equilibrio aristotélico. 


\title{
Atropellos a docentes en cualquier nivel
}

El maltrato al profesor y, por consiguiente, a su autonomía ocurre en los distintos ciclos educativos. Lo que acontece en ámbito colegial puede bien replicarse en el ámbito universitario. Andrés Hurtado García (2013) demuestra lo que está ocurriendo en el contexto escolar:

\begin{abstract}
Ahora, en las mismas circunstancias, son los padres los que insultan a los maestros delante de los hijos. Y los pobres maestros tienen que aguantarse, porque, si se defienden, incluso en los mejores términos, los padres los acusan ante la secretaría de educación, y, como allí creen todo, los que "llevan del bulto" son los inocentes y sufridos educadores. Obviamente, el Gobierno, o sea las secretarías de educación, obran así por simple politiquería y demagogia de pésima ley. (Hurtado García, 10 de diciembre de 2013)
\end{abstract}

Por otra parte, los maestros son culpados por los malos resultados de los estudiantes. Por ejemplo, después del bajo rendimiento de los estudiantes de secundaria en las pruebas PISA (Programme for International Student Assessment) de la Organización para la cooperación y el desarrollo económico, "la mayoría de los analistas centran sus explicaciones en la pobre preparación de los maestros" (Cajiao, 16 de diciembre de 2013, p. 21). Sin embargo, Cajiao (2013) toma una posición distinta y focaliza su atención en otros aspectos: el sistema educativo, las entidades administrativas, nacionales y locales de la misma, y la indiferencia del poder público frente a la educación. Según Cajiao (2013), no se puede responsabilizar únicamente a los maestros por el desempeño de los alumnos. Mas Cajiao (2013) es una excepción, para muchos analistas y para el público en general, esos exámenes se convierten en razones para inculpar o "caerle" a los maestros. Esa predisposición a castigar al docente en el nivel preuniversitario puede colegir fácilmente en una actitud negativa hacia el maestro en general, incluido el universitario. De modo que si nos descuidamos, todo eso puede trasladarse injustamente a las universidades colombianas. 


\section{Técnicas pedagógicas excesivas}

En el campo propiamente universitario, se presentan varios atropellos al profesor. Inicio por analizar los atropellos relacionados con las técnicas docentes, las cuales, son muy populares hoy en día. Entre estas técnicas docentes están: los procedimientos docentes, las reuniones para que los profesores compartan sus experiencias tecnodocentes, las herramientas tecnológicas, etc. Estas técnicas pueden convertirse en atropellos al profesor cuando son excesivas. Por ejemplo, la plataforma Moodle es considerada una herramienta de enseńanza, pero cuando se usa con grupos numerosos de alumnos, lo cual suele suceder, esclaviza al profesor.

De igual modo, esas técnicas no siempre promulgan ideas congruentes. Las técnicas docentes promueven la idea de que el alumno es quien "crea" el conocimiento y, por ende, el "protagonista" de la vida universitaria. Entonces, el profesor se convierte sólo en un guía de aprendizaje y realiza talleres para que el alumno cree. No obstante, en el período formativo de pregrado un alumno difícilmente crea conocimiento, salvo que sea un superdotado. Sería más conveniente aspirar a que el estudiante desarrolle un pensamiento crítico y madure en los valores, como dice el Papa Francisco (2013) en el Punto 64 de su exhortación apostólica Evangelii gaudium.

Por hechos como los notados anteriormente, el maestro se ha esfumado, ha desaparecido. Los grandes maestros, como Sócrates, Aristóteles y Jesucristo, eran reconocidos por su cabal. Mas, en la actualidad, los alumnos desconocen a sus profesores y, cuando se les pregunta, ni siquiera recuerdan los nombres de los mismos. Para empeorar la situación del maestro actual, no se le ha permitido desarrollar su autonomía, es decir, ser él mismo. Por el contrario, se ha contrariado su ser primero: hombre-docente. Esa unión hombre-docente es precisamente el elemento integral de la autonomía docente. Cuando esa autonomía docente se aniquila, solo queda el docente-técnico. En ese camino, los profesores dejan de ser maestros: se convierten en instrumentos que transmiten información pregrabada.

La pre-muerte del profesor me causa quebranto y casi lágrimas, pero debo seguir mi análisis teórico sobre la tecnificación de la educación superior para poder explicar claramente los atropellos a la autonomía docente. ¿No es la tecnificación 
una característica de nuestro tiempo? ¿Acaso, esa tecnificación no se deriva del cientificismo que deshumaniza en tantos aspectos? ${ }^{3}$ Ahora bien, el intelectual debe tener siempre un espíritu crítico ante todo. Incluso, si eso implica tomar una posición contracorriente. En cuanto a los excesos de las ciencias exactas y de la tecnología, el intelectual crítico debería oponerse a rebajar el valor del humano, de su espíritu y de las relaciones interpersonales.

Desde luego, la tecnificación de la educación superior toca dos puntos neurálgicos: la libertad y la vida del maestro. Por una parte, la tecnificación produce que el maestro deba depender de las técnicas, so pena de ser caracterizado como desfasado, decimonónico o anacrónico. Así, el profesor actual queda cada vez más atado a la tecnificación. La otra parte, la vida del maestro, es quizá más grave y absoluta. Aunque ciertas técnicas pedagógicas pueden ayudar un poco, la vida del maestro es el principal canal o vehículo de la enseñanza. Entonces, el ser maestro no puede erigirse en las técnicas; el maestro verdadero transmite una vida, su vida.

Tres maestros de la antigüedad pueden ilustrar cómo se transmiten enseñanzas a través de una vida. Primero, Sócrates, gran maestro griega, dio su vida como máxima expresión de su enseñanza. Él se entregó libremente ante los poderosos del siglo $\mathrm{V}$ a.C., quienes lo acusaban de corromper la moral de la juventud con sus enseñanzas, y bebió cicuta para cumplir con la sentencia le profirieron. Sócrates murió acatando sus dos enseñanzas fundamentales: alejarse de los vicios y mantener la virtud hasta la muerte. Nuestro segundo ejemplo, Aristóteles, siguió líneas similares a Sócrates. Él consideraba que la vida del maestro era lo primero para enseñar y vivió acordemente, ya que estuvo en la Academia de Atenas por más de 20 años y, luego, fundó el Liceo en el que enseñó hasta vísperas de su muerte. El último maestro que quiero mencionar es Jesucristo. Según sus propias palabras, "Soy el camino, la verdad, y la vida", él también creía que él, como maestro, era una vida. Jesucristo, al igual que Sócrates, entrego su vida libremente por sus discípulos. De modo que estos tres grandes maestros estimaron la vida, el testimonio vital en libertad, como lo primero de la maestranza.

3 Remítase a "La resistencia", una obra crítica y esperanzadora, de Ernesto Sábato (2001) para una discusión sobre la noción de cientificismo. 
Nuestros tres maestros ejemplares también utilizaron herramientas técnicas para facilitar el entendimiento de sus mensajes. Sus técnicas principales fueron: la mayéutica platónica, la lógica aristotélica y la parábola de Cristo. Pero, estoy convencido de que lo que más inspiró a los alumnos de estos tres grandes maestros de la humanidad no fueron sus técnicas docentes, sino su estilo de vida. Ese estilo que fue congruente con la verdad y la virtud. En ellos, no hubo ningún signo de corrupción, de incoherencia o de desvío ético. Por el contrario, hubo, en realidad, una vida sanamente seductora, apasionante, digna de emulación. En últimas, la vida del maestro tenía prioridad sobre cualquier otro recurso o técnica docente y era lo que más atraía a sus respectivos magisterios.

Lamentablemente, en la actualidad, parece que lo prioritario es la técnica de la enseñanza, no la vida del maestro. Los papeles se han invertido, aparentemente. Se ha priorizado transmitir información mediante instrumentos electrónicos. Sin embargo, debe aclararse que transmitir información no es enseñar ni educar. Educar es lo propio del maestro. Mas el maestro únicamente consigue educar verdaderamente cuando cuenta con un paradigma vital libre. Desgraciadamente, ya lo profetizó Einstein (n.d.), la tecnología se ha hecho deshumanizante.

Contrario a lo que se creería, los alumnos de todas las épocas, y especialmente los de hoy en día, buscan el testimonio vital del maestro. Los estudiantes no desean el tecnicismo pedagógico, sino un paradigma vital. Este anhelo se debe a que, en muchos casos actuales, los padres no aparecen en la escena vital del hijo. Por lo tanto, los alumnos no encuentran ese paradigma vital en sus padres. Para el estudiante contemporáneo, es muy fácil hallar información, pero no modelos vitales y libres. Hoy, esos modelos parecen tan carentes que muchos de alumnos sólo los encuentran en sus maestros. De modo que la falta de padres debe ser suplida, en alguna forma, por los profesores u otros individuos que puedan convertirse en su guía de vida.

Quizá, lo que más aprecia el alumno es un estilo de vida. En nuestra realidad actual, cunden los seres humanos corruptos, descaminados y sin ideas. Los estilos de vida más comunes y cercanos a los estudiantes están repletos de características negativas. Cuando los alumnos conocen seres humanos a cabalidad, se "encantan". ¿Pero, por qué sucede eso? No sé la respuesta exacta. Intuyo que es debido a que los alumnos 
añoran llenar los vacíos que mencioné anteriormente. En lo más profundo de nuestro ser, los humanos aspiramos a hallar la integridad y la perfección encarnada en nosotros mismos y en los demás. Cuando otros seres humanos representan perfección e integridad, ocupan una posición especial en nuestras vidas.

Contemplar a otros como paradigma de vida, no implica que los alumnos pierdan su propia personalidad. Tampoco se espera que cuando esa persona paradigmática sea un docente, le hagan un culto o le alaben su personalidad. No obstante, sí debe admitirse que ante tanta desfiguración humana, hecho que se evidencia en corrupción ilimitada en el ámbito público y en el privado, el nicho educativo sigue siendo un lugar de oasis para que los estudiantes tengan un referente de dignidad a emular. Es indiscutible que ese referente es lo que el ser humano más anhela. Ello le atrae más que el dinero, el poder o el mero conocimiento científico. Esos tres elementos son hoy supervalorados y apetecibles en la sociedad actual, pero solo sacian al humano momentáneamente.

Tal vez, sea pertinente cerrar este análisis sobre la tecnificación y el tecnicismo docente excesivo reflexionando sobre el significado de las palabras profesor y maestro. Profesor debería ser aquel que "profesa" un estilo de vida y de conocimiento. Igualmente, profesa la entrega de su tiempo y de sus energías vitales a sus alumnos. La palabra maestro indica algo más. Por lo tanto, cuando se llama a alguien por ese nombre, se implica que ese ser tiene un plus. El maestro posee más claridad y experiencia para orientar y guiar a sus alumnos por caminos válidos. Llámese maestro o profesor, ese ser debe encarnar valores humanos tales como el respeto, la puntualidad, el rigor académico, la vida comunitaria y la exigencia en la búsqueda del saber. Sobre todo, como Sócrates, Aristóteles y Jesucristo nos demostraron, el profesor o maestro debe vivir su vida en libertad y entregársela a sus alumnos. Sus vidas, no sus técnicas, han sido un paradigma que ha impactado a millares de seres humanos a lo largo de la historia. 


\section{Homogenización perversa del profesor}

Otro ataque a la autonomía docente relacionado con toda la batería tecno-docente, explicada en la sección anterior, es la homogenización del profesor. Todos los profesores deben tener en su haber pedagógico esas técnicas, dice la mentalidad dominante. Parece que no hay una alternativa distinta a la tecnificación de la educación superior. Probablemente, es un efecto tardío y nefasto de eso que Ortega y Gasset denominó en 1930 como el "hombre-masa" (Ortega y Gasset, 2007, p. 52). Ortega definía esa noción del hombre-masa como "la pavorosa homogeneidad de situaciones en que va cayendo todo el Occidente" (Ortega y Gasset, 2007, p. 47). Cuando reflexiono sobre el hombre-masa en el caso de los docentes universitarios, me surgen dos interrogantes principales: ¿Puede el docente ser víctima pasiva de esas situaciones de estandarización del ser humano? ¿No tiene el docente el deber de oponerse con fuerza a ella?

El fenómeno del hombre-masa, o la homogenización, producen pésimos frutos en la educación. En otros tiempos, uno escuchaba a profesores estupendos y a otros menos hábiles. Al fin de cuentas, se conocían distintos tipos de seres humanos con sus respectivos estilos pedagógicos. De esa manera, se aprendían a valorar a todos y a aceptarlos con sus diferencias. Pero, con la homogenización del cuerpo docente, los alumnos de esta época no conocen una gran variedad estilos educativos o de profesores. En la actualidad, se ataca el pluralismo sano y desaparece la posibilidad de la tolerar distintos estilos magisteriales. Esa homogenización es enormemente dañina para los espíritus de los estudiantes y de los docentes. Además, afecta el espíritu político democrático; así se torpedea la democracia desde ese frente más parroquial de la vida del claustro. Otro fruto pernicioso de la homogenización es la dependencia tecnológica del profesor contemporáneo. Muchos docentes, por ejemplo, han atrofiado sus habilidades expositivas. Con mis propios ojos, he visto el modo en que profesores se han vuelto tan dependientes de la tecnología audiovisual que han ido perdiendo paulatinamente el atractivo de sus exposiciones. Los excelentes expositores que eran los maestros antiguos han ido desapareciendo. 


\section{Exceso de actividades institucionales}

La tercera limitación a la autonomía del profesor es la excesiva cantidad de reuniones, cursos de capacitación y demás actividades institucionales. Estas actividades ocupan muchísimo tiempo del docente, lo cual desmedra la calidad de su principal ocupación: preparar clase. Clase quiere decir calidad, categoría, fineza. Para preparar una clase correctamente, el docente debe seguir la sabia exhortación Tomás de Aquino: "Contemplare, et aliis tradere contemplata", la cual se traduce como "contempla, medita, reflexiona, piensa, y luego entrega eso, lo contemplado". Entonces, si docente desea impartir excelentes clases, requiere de demasiada lectura profunda y de muchas horas de reflexión. Solo así podrá transmitir un conocimiento más cualificado a sus alumnos. Sin embargo, cabe preguntarse si con la excesiva cantidad de actividades institucionales en las que la mayoría de docentes deben participar, se les está dejando tiempo suficiente para la lectura y la reflexión del profesor. Desde mi perspectiva, la respuesta en un rotundo no.

Aunque otras actividades de clase, como talleres, exposiciones y debates, son importantes, la clase magistral es el mecanismo primordial de transmisión de sabiduría en la academia desde la antigüedad. La clase magistral hace honor al maestro, magister; por eso, se les denomina clases magistrales. En estas clases, el maestro entrega un saber depurado, reflexionado, madurado, único, serio, científico y filosófico (Cfr. Ortega y Gasset, 2007b, p. 35). Ese saber excede un mero programa de asignatura. Como dijo Ortega y Gasset (2007b): "En materia de arte, de amor y de academia, no caben tanto los programas" (p. 35). Por esta razón, un buen profesor debe ser ir más allá de cualquier programa académico mediante su investigación y su reflexión.

Pero la realidad de los docentes en la actualidad no podría ser más contraria a lo postulado previamente. El tiempo del docente se va en horas contractuales laborales para cursos, capacitaciones, reuniones, informes y demás. Se supone que todas esas actividades completan el horario laboral del profesor y justifican su contrato, pero irónicamente éstas le quitan tiempo a su ocupación primordial, la clase. Ese supuesto está basado en la idea falaz que la ciencia del profesor es una ciencia infusa. Aún no se 
comprende que ser maestro es un arte perfeccionado mediante la lectura, el estudio, la reflexión y la práctica.

Los resultados de un buen maestro se evidencian en el aprecio y respeto de los alumnos y en la producción de libros y artículos. Sin embargo, según serios estudios en Estados Unidos, el excesivo activismo institucional (participación en reuniones, cursos, etc.) inevitablemente causará que la producción literaria de los docentes se reduzca. Contra esa predicción, podría objetarse que en la academia existen profesores hoy en día que no investigan, sino que se dedican exclusivamente a la cátedra. A esa objeción, se puede responder de la siguiente manera: los "profesores, sólo profesores", a quienes únicamente se les circunscribe al oficio de dictar clases y no se les brinda la posibilidad de escribir, están castrados. Cuando sólo imparten clases y no les queda tiempo para escribir, se comete un atropello contra ellos.

\section{Sesgo en las evaluaciones a los docentes}

Otra limitación al desarrollo de la autonomía docente es la evaluación sesgada del desempeño de los profesores. Las evaluaciones a docentes deben ser existir, máxime después de los abusos descritos en el inicio de este artículo; el problema es cómo están siendo evaluados actualmente. Si los profesores son evaluados por los alumnos mediante instrumentos concretos de evaluación, quedan a expensas de los últimos para ser "manoseados". Por ejemplo, cuando un profesor es riguroso, exigente, serio, puntual, no regala notas y/o no tolera la promoción automática al siguiente curso, los estudiantes tienden a "sacrificarlo" ante el "matadero" de las autoridades administrativas de la institución. Por cierto, he sabido que algunas autoridades administrativas modifican a su conveniencia las evaluaciones realizadas por alumnos. Esas autoridades pueden mermar las calificaciones de aquellos docentes que quieren descartar y así poder justificar el despido.

Para que las evaluaciones a docentes sean adecuadas, éstas deben seguir una lógica diferente. Primeramente, los profesores no deberían ser evaluados en términos inmediatistas. Cuando las evaluaciones son realizadas por alumnos que están cursando una asignatura con un docente en la actualidad, ellos propenderán por 
rebajar calificaciones basándose en hechos recientes y malinterpretados. Por ejemplo, pueden rechazar a un profesor simplemente por ser exigente.

Sin embargo, el simple criterio inmediatista de evaluación utilizado por los alumnos afecta gravemente a la institución educativa y al docente. Las instituciones educativas, como empresas capitalistas despersonalizadas, buscan satisfacer a los alumnos, su sostén económico principal. Por ende, despiden personal docente basándose en las calificaciones de los estudiantes. Dado que los profesores necesitan su salario para sobrevivir, muchos de ellos pueden llegar fácilmente a "venderse" para continuar laborando. Cuando un docente sigue el criterio inmediatista de los alumnos, queda expuesto a convertirse en un profesor que da gustos, que satisface las apetencias inmediatas del alumno. Como no hay apetencia más inmediata del dicente que la nota académica, ese profesor termina acrecentando las notas de su asignatura. Por todo lo anterior, las evaluaciones inmediatistas de los alumnos al profesor son, en el fondo, una carnada de corruptela y le dan "todas las de ganar" a los estudiantes.

En segunda instancia, debería repensarse la precisión de las evaluaciones actuales. La evaluación a los docentes se basa en los testimonios de los alumnos. Dicha evaluación, realizada por los estudiantes mediante sistemas computarizados, no es personal, documentada ni soportada. Incluso, muchos alumnos llenan el formato virtual sobre el desempeño del docente en franca venganza contra el profesor cuando éste es exigente. Por ello, las evaluaciones y los comentarios dignos de crédito provienen, en su mayoría, de cierto tipo de alumnos, los mejores. Pero, en general, es difícil establecer la credibilidad de estas evaluaciones porque son anónimas. Además, en las evaluaciones actuales a docentes, no se presta suficiente atención a pruebas como: evidencias documentales, declaraciones de parte del profesor, experticias, testigos cualificados, etc. Por lo tanto, la evaluación actual no permite examinar todo tipo de pruebas para hallar la verdad real e integral sobre los docentes.

El tercer cambio en la lógica usada para evaluar docentes está relacionado con los criterios de evaluación. La evaluación a maestros debe basarse en criterios como: trayectoria profesoral, producción de artículos y libros y, por supuesto, estilo de vida incorrupto y coherente. Con esos criterios claros, las directivas, los colegas y los alumnos acreditados podrían apreciar mejor al profesor. 
Por último, las evaluaciones a los docentes deberían realizarse cuando haya verdaderos y reales motivos para su descalificación. La descalificación del profesor "viene sola" y se "impone por sí misma", sin necesidad de evaluaciones donde prime la opinión inmediata del alumno. Si, por ejemplo, se observa con espejo retrovisor un retroceso docente, es decir, una disminución real en la calidad del maestro, se debe realizar una evaluación a dicho docente. Antes de tener esos motivos, la evaluación del profesor es innecesaria.

De no realizarse esos cambios que he anotado, la autonomía docente seguirá sufriendo nuevos y repetidos ataques.

\section{Minoridad del docente}

La siguiente limitación a la autonomía del profesor es tratar a los docentes como si fuesen otros alumnos o empleados apenas cualificados. Déjenme ilustrar esta limitación con un simple ejemplo. Tal como los maestros revisan la lista de asistencia de sus pupilos, en cada reunión, se verifica la asistencia de los docentes. Francamente, es un control antipático que parece estar basado en la asunción que los docentes son menores de edad y que inocula una actitud de desconfianza hacia los mismos

Es posible que esa actitud se relacione con que el profesor está mal catalogado en la opinión pública. Por ejemplo, Perry (2014) sostiene que "los expertos" coinciden en que el bajo rendimiento estudiantil en las pruebas PISA se debe a "la mala calidad de la docencia, aunque hay excepciones insulares" (p. 7). No obstante, entre la opinión pública también hay posiciones a favor de los docentes. Como ejemplo de la confrontación entre esos dos extremos, podemos citar la réplica de Hurtado García (2014) a las aseveraciones de Perry (2014):

Dejémonos de vainas, ¿sí? Y digamos la verdad. Quedamos catalogados, para escarnio mundial, en los últimos lugares de las pruebas PISA. Inmediatamente, el Gobierno, en uso de sus farisaicas facultades, y los medios de comunicación, especialmente los radiales, con irresponsabilidad manifiesta, vertieron toda la responsabilidad sobre los maestros. ¡Cojan oficio y seriedad, señores! ¿Ya se 
olvidaron del decreto dos treinta y de la promoción automática, según los cuales los vagos y sus padres alcahuetes salían premiados?

Hemos oído decir a muchos estudiantes: 'yo pasé todo el bachillerato gracias a la promoción automática'. Alumnos con 5, 6, 7 y 8 materias perdidas, como se dice en el argot estudiantil, pasaban tranquilamente al curso siguiente. Esto sí era la más impresionante aberración, creada mediante decreto del Estado. Ya no existen estas disposiciones legales, pero ha quedado su resabio, el espíritu de vagancia en alumnos y padres de familia. Esta es la causa de nuestro escarnio mundial. (p. 18)

Aunque Hurtado García (2014) se refiere en su artículo a los colegios, esa mala imagen del profesor se traslada fácilmente a las instituciones de educación superior, como por efecto reflejo. Quizás, será por esa mala imagen que nos toman lista de asistencia en todas las reuniones, por pequeñas que sean. Pero sigamos leyendo a Hurtado García (2014) para ver si, en realidad, los males del mundo educativo radican en los maestros:

Por otro lado, el ambiente social, político y conflictivo que vive el país no es el más propicio para el estudio. '¿Para qué estudia uno - decía un alumno- si mi papá, que es ingeniero, maneja taxi porque no consigue empleo?' ‘¿Para qué se mata uno estudiando -afirmaba un alumno de una ciudad fronteriza- si con pasar un kilo de droga le pagan a uno hasta medio millón de pesos?’

En Colombia, además, por obra sobre todo de algunos periodistas irresponsables, parece que es el hazmerreír de la sociedad y se lo trata muchas veces hasta con burlas y chistes flojos. (p. 18)

Entonces, según Hurtado García (2014), los problemas de la educación en Colombia no se deben a los docentes, sino al sistema educativo en su conjunto (padres de familia, alumnos, periodistas, legisladores y demás). Sin embargo, Hurtado García (2014) también afirma que los maestros tienen parte de la culpa de su mala catalogación, ya que algunos de ellos son mediocres. Reconozco que existen esos casos y que esa culpabilidad es verídica, pero considero que debería haber una actitud de confianza y 
respeto hacia los profesores íntegros. Esa actitud debería traducirse, por ejemplo, en tratar al profesor como un mayor de edad responsable, quien conoce su obligación de asistir a dichas reuniones y enfrenta las consecuencias de su eventual inasistencia.

\section{Dependencias institucionales y administrativas}

La sexta limitación a la autonomía del profesor es la dependencia actual a ciertas figuras e instituciones. Por una parte, hay una dependencia mental respecto de ciertas figuras como el rector de la institución universitaria o el decano de la facultad correspondiente. Entonces, me pregunto qué se recordará más a posteriori, el profesor o la institución y sus figuras. Por ejemplo, ¿quién recuerda ahora cuál era el rector cuando Tomás de Aquino era profesor o, al menos, en qué universidad enseñaba? En nuestros tiempos, los aplausos se los lleva la administración, aunque el docente figurará más en la historia. Por ahora, el docente es considerado muchas veces un simple y opaco empleado.

No obstante, debería lograrse un sano equilibrio entre la institución y las personas que la conforman. Las instituciones son necesarias y útiles, pero éstas no tendrían prestigio sin las personas que las integran. Las personas no pasan, se quedan en la memoria y constituyen las instituciones. Por este motivo, en las universidades debe reconocerse el mérito del profesor y del conjunto institucional. No deberíamos aceptar exagerar el institucionalismo que estamos presenciando en la actualidad. Ese institucionalismo es un ismo, es decir, una actitud exagerada.

Por otra parte, las instituciones universitarias y los docentes se han vuelto dependientes de otras instituciones como Colciencias. Figurar en una categoría alta de investigación de Colciencias o publicar en una revista indexada es lo que atrae, según las instituciones. Por eso, estar o no en una categoría de investigación produce grandes ansiedades entre los profesores. No obstante, quien recibe el reconocimiento y la ovación, en la mayoría de los casos, es la universidad, no el docente-investigador. Para colmo de males, esas publicaciones raramente llegan a servir a la sociedad o a ser leídas por el público en general. Paradójicamente, las publicaciones serias que llegan al público en general con artículos de impacto social y científico, 
como UN Periódico de la Universidad Nacional de Colombia, no son indexadas. Además, nuestras instituciones no siempre responden a nuestra realidad nacional. Por ejemplo, ni Colciencias ni el Ministerio de Educación Nacional contemplan factores como la proyección social para otorgar acreditaciones. Nuestras universidades latinoamericanas, pobres en recursos, deberían distinguirse más por su servicio a los necesitados de la sociedad que por la investigación y la acreditación formal. Pero nuestras universidades no comprenden eso y persiguen asemejarse a las universidades estadounidenses o europeas. Siguen el "gringocentrismo" o el eurocentrismo. Ese es un craso error porque nosotros no podemos dedicar tantos recursos y energías a la investigación como en los países europeos y norteamericanos.

Nosotros deberíamos procurar ser nosotros mismos, ser autónomos. Deberíamos preponderar la proyección social, por ejemplo. En nuestro medio subdesarrollado, esa proyección es necesaria y relevante. Los europeos y los norteamericanos se maravillarían de saber que en Latinoamérica las universidades atienden a las necesidades de los pobres. Las universidades y las instituciones nacionales deben fomentar la investigación seria y que, sobre todo, atienda realmente a nuestros problemas sociales.

En síntesis, el panorama de la institucionalidad en la educación superior colombiana actual está lejos de ser ideal. El profesor termina siendo opacado y la institución ensalzada. Parece que el reconocimiento y el prestigio se obtienen ahora según una categoría de investigación, una acreditación o una figura administrativa. Así, la universidad y/o la administración ganan mayor plausibilidad, en desmedro del profesor. Sin embargo, en algunos casos, los profesores logran conservar su autonomía y mantener su prestigio más allá de las instituciones y las administraciones.

\section{Defectos contractuales}

Una limitación más a la autonomía docente se halla los deficientes contratos laborales del profesor. Actualmente, la mayoría de los profesores se contratan por un semestre académico (escasos cuatro meses) o por 11 meses. El número de profesores 
contratados a término indefinido es mínimo. ¿No es tipo de contratación una restricción a la autonomía de los maestros?

Otra deficiencia en los contratos laborales del profesor son las cláusulas contractuales. Las estipulaciones en esas cláusulas son tan minuciosas y milimétricas que son deshonrosas para el profesorado. Por ejemplo, se decreta cuántas horas debe dedicar el maestro a la investigación, las clases, las reuniones, el claustro y la atención a alumnos. Incluso, en algunos contratos se establecen el número de horas que el maestro debe preparar sus clases, aunque comparada con las demás cantidades es mínima. Eso supone que el profesor posee una ciencia infusa que adquirió previamente y por arte de magia.

Esas cláusulas milimétricas son ofensivas y restringen al profesor de manera exasperante e irreal. Dan la sensación de que la institución educativa tiene subyugado al profesor. Pareciera que con esas cláusulas la institución le estuviera diciendo al docente: "Primero, agradézcame por contratarlo. Luego, cumpla con cada milímetro de las actividades que le impongo". Esa situación se asimila a la de los futbolistas de hoy en día. Ellos pueden ganar mucho dinero, a diferencia de los profesores, pero no son verdaderamente libres. Ellos dependen de un manager, de un equipo de fútbol o de otras instituciones deportivas que disponen de ellos. Deberíamos preguntarnos si los deficientes contratos laborales de los profesores colombianos reflejan una gran categoría en la escala social. Entre las conclusiones del Foro $\mathrm{I}+\mathrm{E}=\mathrm{D}$ (Innovación, más Educación, igual Desarrollo), realizado en el mes de mayo de 2014 en Colombia, se estableció la necesidad de revalorizar al maestro. En el periódico El Tiempo (2014b), se afirmó textualmente: "hay que reivindicar su papel socialmente [refiriéndose a los maestros]" (p. 2).

Los defensores de la "economía" de los claustros podrían responder a las críticas sobre la contratación y la valoración de docentes universitarios. Sin embargo, la valorización del profesor debe pasar por un repensar estas contrataciones. Deberían poner la mano en el corazón de las finanzas para que ellas sean más generosas con los maestros. Se debería corregir la inequidad de pagos e inversiones entre los distintos frentes de la universidad. 
La inmensa mayoría de los profesores no están satisfechos con sus bajos salarios, aunque no lo griten a viva voz. Pero es hora de romper el silencio. La inequidad salarial tradicional no puede seguir ocurriendo. Deberíamos hallar maneras de mejorar las condiciones laborales del maestro al máximo, incluida su contratación y su paga. ¿Acaso, no podrían elevarse los ingresos del profesor un poco más si se sacrifican otros ítems quizá menos importantes de los claustros? Por ejemplo, se debería poner más énfasis en la justa remuneración del maestro que en la construcción de edificios innecesarios.

Es cierto que las universidades requieren hoy mucho más dinero, edificios inteligentes, tecnologías de punta y bases de datos avanzadas que en el pasado. Todo ello con el fin de propiciar la investigación de alto nivel. Esto ha causado que efectos colaterales como las "admisiones para el desarrollo". Ese es un criterio que se aplica durante el proceso de admisiones a la universidad a aquellos solicitantes que tienen padres muy adinerados. En alguna medida, los solicitantes que cumplen con ese criterio son preferidos, así sus notas en el colegio o en los exámenes de admisión a la universidad no sean muy altas. En tal caso, los estudiantes pobres terminan siendo excluidos en aras de los hijos de ricos (Cfr. Michael Sandel, 2011).

De hecho, reflexionemos sobre el propósito de la universidad:

Su propósito no es maximizar los ingresos, sino servir al bien común por medio de la enseñanza y la investigación. Es verdad que la enseñanza y la investigación son caras, y las universidades dedican muchos esfuerzos a conseguir fondos. Pero cuando el objetivo de hacer dinero predomina hasta el punto de que la política de admisiones se rige por él [...] es que la universidad se ha apartado mucho de los bienes académicos y cívicos que son su principal razón de ser. (Sandel, 2011, p. 208)

Los esfuerzos de las universidades para conseguir fondos que critica Sandel (2011) se hacen evidentes cuando vemos semestre a semestre publicidades en la gran prensa de casi todas las universidades para vender su institución. Sabemos que esa publicidad cuesta millones. Por eso, se nos llaga el interior al pensar en la disparidad entre el gasto publicitario y la remuneración al docente. Entonces, surgen mis interrogantes: 
Si las universidades ya han ganado un good will por ańos, gracias a exalumnos, acreditación, docentes, etc., ¿no podrían evitar esas propagandas millonarias?; ¿no podría disminuirse la publicidad para hacer más austera y generosa la paga a los profesores? (Cfr. El Tiempo, 18 de mayo de 2013)

\section{Conclusiones}

Las deficiencias de la educación colombiana han causado un pugilato que bien merece ser analizado. En un bando, están los que acusan al profesor de ser el causante primero de la mala educación en Colombia. Su ataque a los profesores sigue campante y rampante, como se pudo demostrar en este artículo. Se inculpan a los educadores de todos los ciclos de educación (primario, secundario y superior), sin distinción alguna. Otros contrincantes afirman que la culpa no es de los maestros, sino de un conjunto de factores que integran e influyen el sistema educativo. No obstante, lo importante en medio de esta lid es recordar que el eje de la educación es la docencia. Por consiguiente, como se ha reiterado en este artículo, es necesario defender al docente y a su autonomía.

Desde luego, todo lo anterior no desmedra de la necesaria responsabilidad del maestro. Si hablamos de los derechos del maestro, también debemos hablar de sus obligaciones y responsabilidades. Especialmente, hoy, cuando presenciamos una subcultura de los deberes en todos los órdenes. La omisión de los deberes de los ciudadanos colombianos se refleja hasta en la Constitución Política de 1991. Ella se centró tanto en los derechos (contenidos en los artículos 11 a 94) que sólo dedicó un artículo, el 95, a los deberes. Por casos como ese, se transmite la idea de que los derechos priman sobre los deberes; cuando, en realidad, deben ir a la par.

El profesor no puede basarse en un saber eterno e inmodificable, semper idem. Ese anquilosamiento es dañino. En el maestro debe haber una ética del trabajo intenso: lectura constante, investigación continua, actualización ininterrumpida, reflexión permanente y criticidad intelectual. Además, su labor debe ser en pro del bien social. Por ende, debe entregarse generosamente a los alumnos que más lo necesitan, aquellos que nunca han contado con guías u orientadores vitales e intelectuales. Asimismo, 
deberá mejorar el claustro mediante la sana convivencia y el sentido de pertenencia institucional.

Finalmente, debemos escuchar la exhortación principal de los distintos foros educativos: tenemos valorar a aquellos maestros excelentes e íntegros. La formación de dichos maestros solo se alcanza cuando los dejan ser, cuando son autónomos, y puede durar toda una vida. Esa vida del maestro luego se convierte en un paradigma. Esperemos que estos maestros ejemplares logren promover la revalorización social de los docentes en general y, por ende, su autonomía. 


\section{REFERENCIAS}

Cajiao, F. (2013, 16 de diciembre). No hay mal que por bien no venga... El Tiempo. Sección Debes leer, p. 21.

El Tiempo (2014a, 17 de marzo). La docencia en la universidad. Sección Debes saber, p. 4.

El Tiempo (2014b, 9 de mayo). El Ministerio de Educación en pro de la educación. Sección Debes saber, p. 2.

Einstein (n.d.). Einstein-idiotizados por la tecnología. Extraído el 12 de marzo de 2014 de Nómade Cósmico: https://nomadecosmico.wordpress.com/2013/11/06/a-einstein -idiotizados-por-la-tecnologia/

Hurtado García, A. (2013, 10 de diciembre). Yo no soy maniático, ¡qué va! El Tiempo, Sección Debes leer, p. 22.

Hurtado García A. (2014, 21 de enero). La eficiencia del derecho a la educación. El Tiempo, Sección Debes leer, p. 18.

Papa Francisco (2014). Exhortación apostólica Evangelii gaudium. Bogotá: San Pablo.

Perry G. (2014, 19 de enero). La educación en el contexto El Tiempo, sección debes leer, p. 7

Ortega y Gasset, J. (2007a). La rebelión de las masas. Madrid: Austral.

Ortega y Gasset, J. (2007b). ¿Qué es la filosofía? Madrid: Austral.

Sábato, E. (2001). La resistencia, Barcelona: Seix Barral.Sandel, M. (2011). Justicia, Debate. 